prof. dr hab. inż. Jerzy Madej

dr hab. inz. Marian Medwid, prof.nadzw.

dr inz. Rafal Cichy

mgr inz. Wojciech Jakuszko

mgr inz. Tomasz, Nowaczyk

Instytut Pojazdów Szynowych ,TABOR”

\title{
Modułowy system transportu naczep siodłowych na wózkach kolejowych w ruchu kombinowanym kolejowo-drogowym
}

\begin{abstract}
$W$ artykule przedstawiono kolejne, opracowane w IPS „TABOR”, innowacyjne rozwiazanie środka transportu kolejowego przeznaczonego do przewozu naczep siodlowych. Zaprezentowano koncepcje systemu transportowego z poziomym załadunkiem naczep na dwucześsciowa platforme kolejowa złożona z tylnego $i$ przedniego uktadu biegowego.

Prezentowany projekt koncepcyjny systemu jest wynikiem prac badawczych prowadzonych $w$ ramach realizacji projektu rozwojowego $\mathrm{nr}$ R10-0065-10 „,System transportu naczep drogowych na wózkach kolejowych $w$ kombinowanym ruchu kolejowo - drogowym".
\end{abstract}

\section{Wstęp}

$\mathrm{Na}$ polskich drogach użytkuje się ponad milion naczep siodłowych, które degradują przyśpieszonym tempie nawierzchnie dróg i środowisko naturalne przez emisję $\mathrm{CO}_{2}$ oraz hałasu i drgań podłoża.
Uciążliwości towarowego transportu drogowego odczuwa cała Europa, dlatego w odpowiednich dyrektywach Komisja Europejska zaleca, aby część środków transportu drogowego skierować na tory 
kolejowe. Komisja Europejska promuje i dofinansowuje programy badawcze, których efektem byłoby przenoszenie części naczep siodłowych $\mathrm{z}$ dróg na środki transportu kolejowego.

W Instytucie Pojazdów Szynowych „TABOR” w Poznaniu od wielu lat prowadzone są prace naukowobadawcze nad poszukiwaniem innowacyjnych rozwiązań środków transportu kolejowego, przystosowanych do przewozu naczep siodłowych. W ostatnim dwudziestoleciu opracowano projekty i wykonano prototypy nowatorskich rozwiązań wagonu niskopodwoziowego (system ruchoma szosa) oraz dwa projekty taboru bimodalnego, wdrożone na etapie prototypu.

Pierwszy prototyp przystosowano do dużych prędkości w ruchu towarowym $\mathrm{V}_{\max }=160 \mathrm{~km} / \mathrm{h}$, drugi prototyp wykonano na bazie standardowego wózka Y25 do ruchu „S” i „SS” z prędkością $100 \mathrm{i}$ $120 \mathrm{~km} / \mathrm{h}$ w zależności od wielkości nacisku zestawu kołowego na tor. Instytut prowadzi dalsze prace badawcze, których efektem jest przedstawione poniżej kolejne, innowacyjne rozwiązanie systemu transportowego.

\section{Projekt koncepcyjny systemu.}

Przedmiotem projektu jest modułowy system dwunaczepowy przedstawiony na rys. 1 . System jest przeznaczony do transportu standardowych naczep z osiami drogowymi wyposażonymi whamulec tarczowy i rozstawie opon $2100 \mathrm{~mm}$, z oponami o maksymalnej szerokości $\sim 400 \mathrm{~mm}$ (opony 19,5" i 22.5 " dla obciążenia $90 \mathrm{KN}$ na oś), oraz z osiami drogowymi z oponami o rozstawie 2100 i $2040 \mathrm{~mm}$ i nacisku osi drogowej $80 \mathrm{KN}$.

Pokazany na rys. 1 skład modułu dwunaczepowego jest sformowany z naczepy 1 , oraz platformy kolejowej złożonej $\mathrm{z}$ tylnego układu biegowego 2 i przedniego układu biegowego 3. Tylne układy biegowe są połączone krótkospiętym urządzeniem pociagowo-zderznym 4, a przednie układy są wyposażone $\mathrm{w}$ urządzenia pociagowo-zderzne 5 , przeznaczone do łączenia kolejnych modułów dwunaczepo- wych oraz do połączenia modułu lub zestawu modułów z końcem konwencjonalnego pociąu towarowego.

Na rys. $2 \mathrm{w}$ widoku od przodu naczepy przedstawiono naczepę posadowioną na ramie nośnej tylnego układu biegowego.

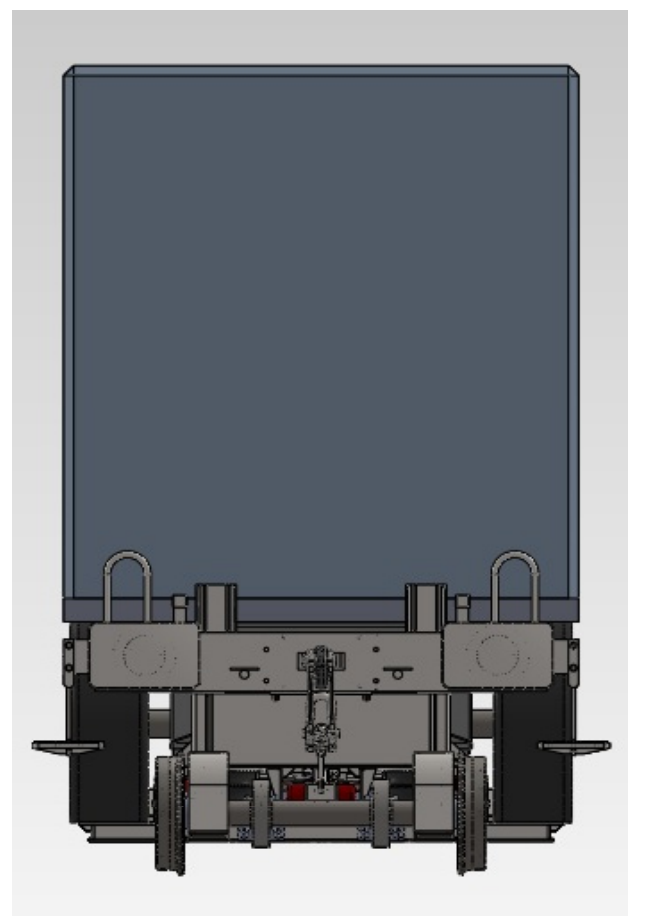

Rys. 2. Naczepa na platformie kolejowej, widok z przodu naczepy

\section{Terminal przeladunkowy i etapy zaladunku}

Terminale do załadunku/rozładunku możemy zgodnie z [3] podzielić na dwie główne grupy. Pierwsza grupa związana jest z systemami Roll-on-Roll-off „Ro-Ro". Systemy te charakteryzują się tym, że załadunek i wyładunek pojazdu drogowego na systemy transportu kombinowanego odbywa się na ich własnych kołach. Druga grupa Lift-on-Lift-off „Lo-Lo” to systemy w których załadowywanie i wyładowywanie odbywa się z wykorzystaniem urządzeń podnoszących. Nowoprojektowany system zaliczyć

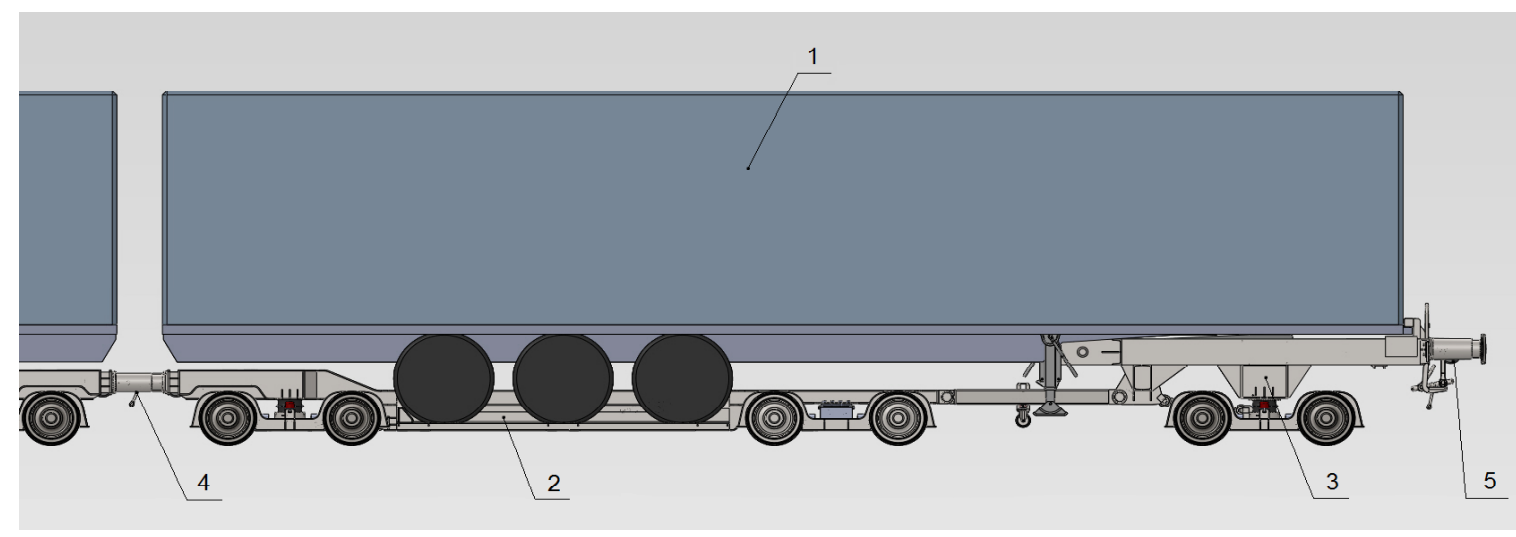

Rys. 1. Widok ogólny systemu 
można do systemów „Ro-Ro”. Oznacza to, że wymagania dotyczące wyposażenia terminalu mogą być ograniczone do niezbędnego minimum. Oprócz stacji bazowych, które winy być wyposażone w odpowiednie stacjonarne urządzenia od kontroli, napraw i konserwacji elementów platformy, można do systemu włączać praktycznie dowolne bocznice. Taka zdolność systemu do łatwego włączania kolejnych podmiotów stanowi niewątpliwą zaletę systemu. Włączenie może stanowić przedsięwzięcie krótkoterminowe nawet jednorazowe, oraz długoterminowe. Elementem istotnym w przypadku długo- lub krótkoterminowym jest obsługa terminalu. Przy operacjach krótkoterminowych może zaistnieć konieczność dowozu obsługi lub jej podróż z ładunkiem. Systemy takie można tworzyć jako systemy transportu towarzyszącego, czyli transport z kierowcą (obsługą). Przy inwestycjach długoterminowych korzystne może być przeszkolenie obsługi i jej stacjonowanie na miejscu docelowym. Omawiany system może zostać wykorzystany np. do dostarczania materiałów do budowy autostrad. Budowane terminale maja w tym przypadku charakter tymczasowy a ich lokalizacja jest związana z postępem inwestycji. Możliwości wykorzystania systemów transportu kombinowanego, w szczególności bimodalnego do budowy autostrad przedstawiono w [7].
Rys.3 przedstawia poszczególne fazy montażu naczepy na platformie kolejowej. W pierwszym etapie, do stojącego na terminalu zespołu sprzęgniętych dwóch tylnych układów biegowych, należy dostawić pomosty najazdowe przygotowane do wprowadzenia kół drogowych naczepy z poziomu terminalu na poziom półek ram nośnych, oraz podjechać tyłem naczepy w pobliże osi toru, tak aby koła naczepy ustawione były przed pomostami najazdowymi. W drugim etapie zostaja opuszczone nogi podporowe naczepy i wyjazd ciagnika spod naczepy. W trzecim etapie pod przód naczepy wprowadza się przedni układ biegowy. W ostatnim etapie połączona naczepa z przednim wózkiem wprowadzona zostaje na półki ramy nośnej tylnego układu biegowego, przedni układ z tylnym zostają połączone w jeden człon modułu oraz opróżnione zostają miechy nośne naczepy.

Przedstawione na rysunku 4 symulacje pokazują pracę terminalu dla omawianego systemu.

\section{Skrajnia taboru}

Skrajnię taboru przedstawiono na rys.5, gdzie rys.5a pokazuje naczepę wyposażoną w osie drogowe z oponami o nośności $90 \mathrm{KN}$ na oś o rozstawie opon $2100 \mathrm{~mm}$ i szerokości $385 \mathrm{~mm}$.
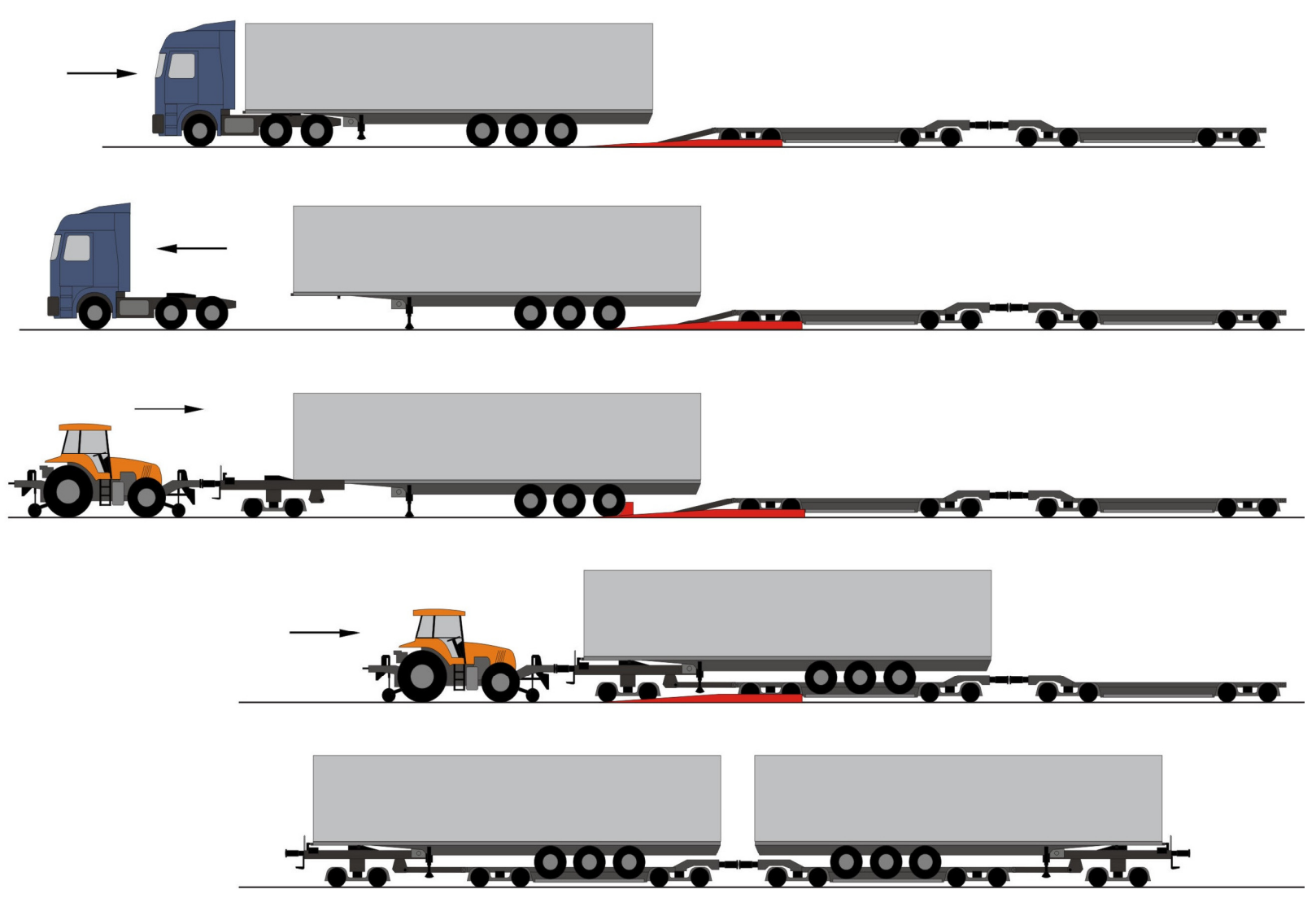

Rys. 3. Etapy załadunku 

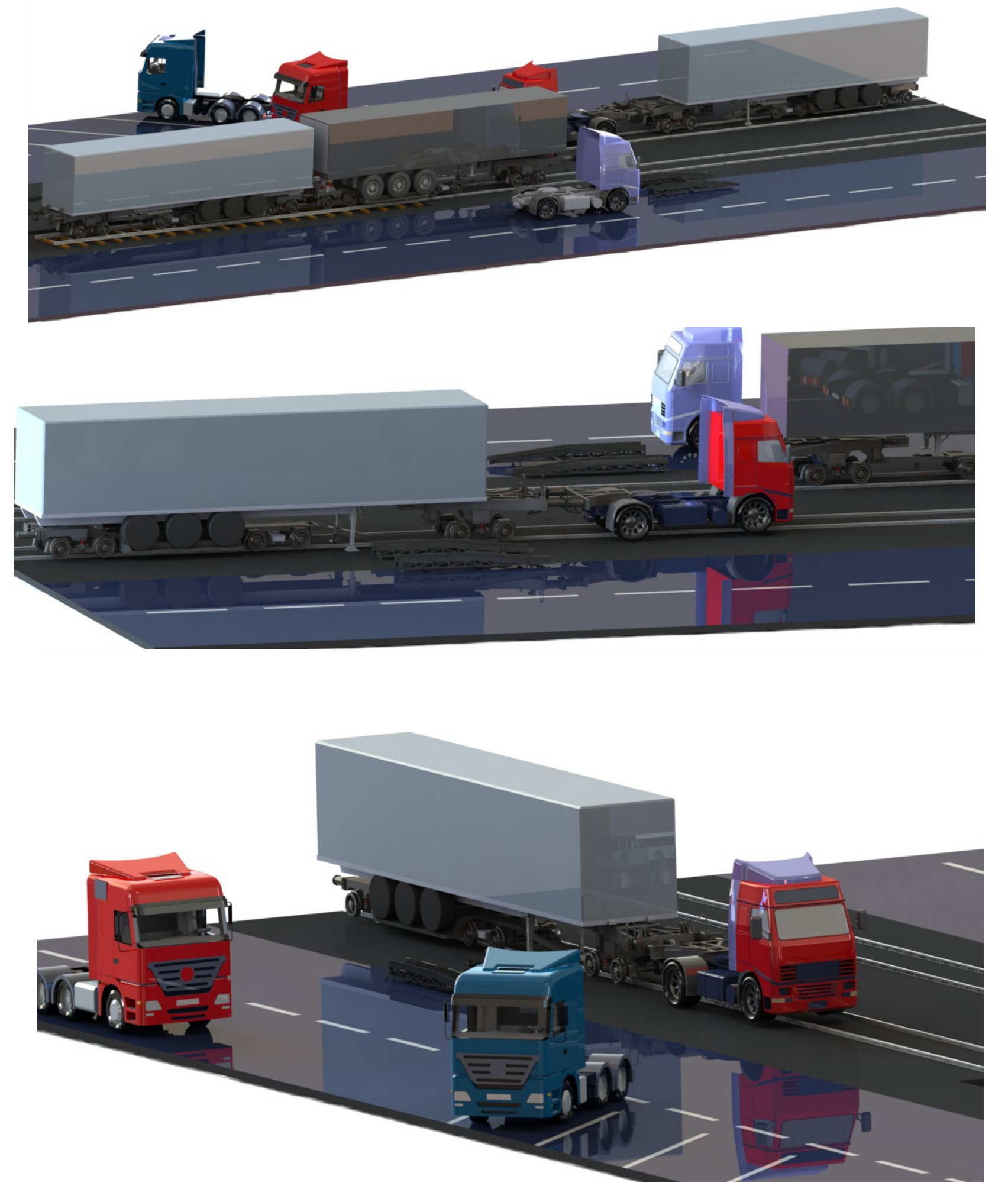

Rys. 4. Przykład symulacyjny pracy systemu na terminalach

Na rys.5b pokazano gabaryt naczepy na tle zarysu skrajni dla naczepy z osiami drogowymi przystosowanymi do nacisków na oś $80 \mathrm{KN}$, dopuszczonym dla standardowych naczep drogowych.

W części dolnej skrajni przedstawiono zarys skrajni określony w przepisach 505-1 obowiązujący dla wszystkich rodzajów taboru kolejowego.

Dopuszczalny w górnej części gabaryt taboru eksploatowanego w korytarzach transportowych wyzna- czonych dla transportu kombinowanego określają przepisy UIC 506, które dotyczą powiększonych gabarytów taboru.

Przytoczone przykłady rysunkowe pokazują, że standardowa naczepa drogowa $\mathrm{w}$ obu przypadkach mieści się $\mathrm{w}$ dolnej części w gabarycie wg UIC 505, a w górnej części w gabarycie GB1 wg przepisów UIC 506. 
a)

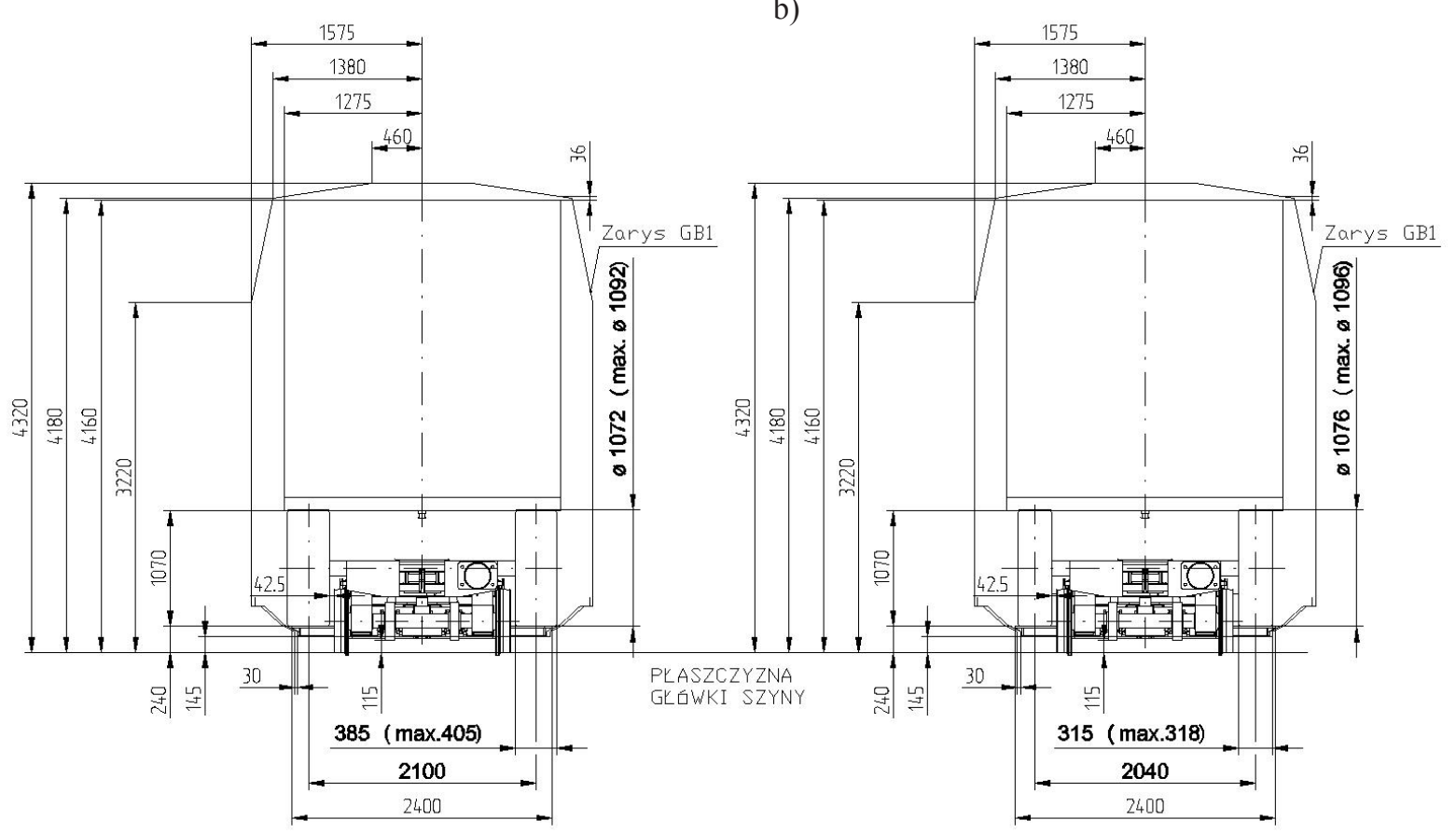

Rys. 5. Skrajnia taboru, a) osie drogowe o rozstawie opon $2100 \mathrm{~mm}$ i szerokości opon $385 \mathrm{~mm}$, b) osie drogowe o rozstawie o $2040 \mathrm{~mm}$ i szerokości opon $315 \mathrm{~mm}$

\section{Podsumowanie}

Prezentowana koncepcja systemu jest wynikiem kolejnego etapu analiz projektowanych $\mathrm{w}$ trakcie realizacji projektu rozwojowego. Opracowane wcześniej koncepcje prezentowane w publikacjach $[4,8]$ stanowiły podstawę dalszego rozwoju projektu dla osiagnięcia zakładanych parametrów eksploatacyjnych oraz stworzenia rozwiązania konkurencyjnego do systemu ,ruchoma szosa”. W prezentowanym systemie transportowym zastosowano zestawy kołowe o średnicy kół $580 \mathrm{~mm}$ (średnica kół w systemie „ruchoma szosa” wynosi od 380-450 mm). Przeprowadzone przez pracowników naukowych Politechniki Warszawskiej symulacyjne badanie bezpieczeństwa przed wykolejeniem na torze wichrowatym o promieniu łuku $150 \mathrm{~m}$ oraz badania stateczności ruchu dwuczłonowego modułu pociagu wykazały, że pojazd spełnia wymagane kryteria bezpieczeństwa ruchu oraz jest zapewniony stateczny ruch pojazdu z prędkością eksploatacyjną $V_{\max }=120 \mathrm{~km} / \mathrm{h}$.

Jednym z głównych osiagniętych celów jest możliwość eksploatacji systemu na szlakach spełniających wymagania skrajni GB1, gdzie górny poziom dachu naczepy może być usytuowany na maksymalnej wysokości $\sim 4180 \mathrm{~mm}$. W systemie „ruchoma szosa" poziom dachu naczepy znacznie przekracza wysokości $4180 \mathrm{~mm}$. Prezentowany system może stanowić konkurencyjne rozwiązanie dla eksploatowanych systemów „ruchoma szosa” oraz „Modalohr".

\section{Literatura}

[1] Medwid M.: Polski system transportu kolejowo drogowego (bimodalnego) typu TABOR, Poznań 2006, Wydawnictwo Instytut Pojazdów Szynowych „TABOR”,

[2] Medwid M.: Studium tworzenia intermodalnych środków technicznych transportu ladowego $w$ szczególności taboru bimodalnego, Poznań 2008, Wydawnictwo Politechniki Poznańskiej,

[3] Terminology on combined transport. CEMT/CS/ COMB/TERM(99)6/Rev.2.

[4] Medwid M., Stawecki W., Cichy R.: Innowacyjne rozwiazanie systemu do transportu kombinowanego, kolejowo - drogowego. XIII Międzynarodowa Konferencja Naukowa QSET 2011 Jakość, bezpieczeństwo $i$ ekologia $w$ transporcie.

[5] UIC 505-1:2006. Pojazdy kolejowe. Skrajnia pojazdów,

[6] UIC 506:2008. Reguty dotyczace zastosowania skrajni powiększonych $G A, G B, G B 1, G B 2, G C, G I 3$.

[7] Medwid M., Cichy R.: Koncepcja wykorzystania bimodalnej techniki transportu, do budowy dróg $i$ autostrad. Pojazdy Szynowe 3/2009

[8] Medwid M., Cichy R., Nowaczyk T.: Model strukturalny systemu transportu naczep drogowych na wózkach kolejowych $w$ ruchu kombinowanym kolejowo - drogowym. Pojazdy Szynowe 2/2011. 